\title{
Participatory Action Research with Daddiri and Ganma: Methodology Co-Design with Aboriginal Community members.
}

Hepsibah Sharmil ( $\nabla$ hepsibah.srs@drmgrdu.ac.in )

Principal Chettinad College of Nursing, Chettinad Academy of Research and Education

https://orcid.org/0000-0003-0893-3123

Janet Kelly

Adelaide Nursing School: The University of Adelaide Adelaide Nursing School

Margaret Bowden

Em Bee's Editing, South Australia

Imelda Cairney

Central Adelaide Local Network, Older Persons Mental Health Service

Joanne Else

Family Matters (SA) Lead, Adelaide

Cherrie Galletly

The University of Adelaide Discipline of Psychiatry

Lisa Hahn

Ramsay Health Care Australia: Ramsay Health Care Ltd

Dennis Liu

The Adelaide Clinic, Ramsay Health Care (SA) Mental Health Services

Coral Sharmil Wilson

Aboriginal Kauna Elder, Co-researcher, Cultural Advisor

Charlotte de Crespigny

Adelaide Nursing School: The University of Adelaide Adelaide Nursing School

\section{Research}

Keywords: Participatory action research (PAR), Ganma, Dadirri, Aboriginal knowledge, Aboriginal, Indigenous, comorbidity, substance abuse, alcohol, mental health

Posted Date: December 28th, 2020

DOl: https://doi.org/10.21203/rs.3.rs-134924/v1 
License: (c) (i) This work is licensed under a Creative Commons Attribution 4.0 International License. Read Full License

Version of Record: A version of this preprint was published at International Journal for Equity in Health on July 12th, 2021. See the published version at https://doi.org/10.1186/s12939-021-01493-4. 


\section{Abstract}

Background: This paper discusses the process of co-design of a de-colonising participatory methodology that enabled an international PhD student to work respectfully with Aboriginal community members and Elders, health professionals and consumers, and non-Indigenous service providers in a drug and alcohol and mental health comorbidity project in Adelaide, South Australia. The Comorbidity Action in the North project sought to redesign services to better meet the needs of local people affected by drug, alcohol, and mental health comorbidity. This arm of the study focused on the needs of Indigenous peoples.

Methods: The PhD student, Aboriginal Elder mentor, Aboriginal Working Party and supervisors (the research team) sought to co-design a methodology that could address the following challenges: many Aboriginal people deeply distrust Western research due to past poor practices and a lack of implementation of findings into practice; Aboriginal people often remain unheard, unacknowledged and unrecognised in research projects; drug and alcohol and mental health comorbidity experiences are often distressing for Aboriginal community members and their families; attempts to access comorbidity care often result in limited or no access; Aboriginal community members experience acts of racism and discrimination as health professionals and consumers of health and support services; and, the PhD student was an international student with no existing relationship with local Aboriginal community members. The research team considered deeply how knowledge is shared, interpreted, owned and controlled, by whom and how, within research, co-morbidity care and community settings. The PhD student was supported to co-design a methodology that was equitable, democratic, liberating and lifeenhancing, with real potential to develop feasible solutions.

Results: The resulting combined Participatory Action Research (PAR)-Dadirri-Ganma methodology sought to create a bridge across Western and Aboriginal knowledges, understanding and experiences. Combined mentoring by senior Elders, Indigenous methodologies Dadirri (deep listening) and Ganma (two-way knowledge sharing), and Western PAR.

Conclusions: Concepts within this paper are shared from the perspective of the PhD student with the permission and support of local Elders and Working Group members. The intention is to share what was learned for the benefit other students, research projects and community members who are beginning a similar journey.

\section{Background}

Western Research is often viewed as untrustworthy and unwelcome by many Indigenous peoples, within Australia and worldwide (1). This is due to research being conducted on Aboriginal people as part of colonising practices. Research may be conducted solely for the benefit of non-Indigenous researchers, while Indigenous priorities, benefits and research approaches are ignored.

This paper discusses the process of co-designing a Participatory Action Research (PAR) methodology that combined Western and Indigenous understandings of what constitutes good collaborative research 
in relation to improving local health service delivery. The South Australian multi-phase PAR 'Stopping the Run Around': Comorbidity Action in the North (CAN) project sought to make recommendations for improvements to local mental health and alcohol and other drugs (MH-AOD) comorbidity services for people aged 12 years and over. When no Aboriginal or local non-Aboriginal researcher applied to conduct the Aboriginal arm of the project, the main author (HS), at the time an international PhD student, was engaged to undertake the work. The innovative methodology was developed to enable her to work respectfully and effectively with Aboriginal community members in the northern suburbs of Adelaide (2).

When considering the best approach to choosing or designing a methodology, a number of challenges needed to be considered. First was the deep distrust of Western research held by many Aboriginal people (3), resulting from repeated experiences of being unheard, unacknowledged and unrecognised in research and health services planning and reform (4). There was also frustration with the lack of implementation of research findings into practice. In addition, the subject matter of this research project was drug and alcohol and mental health comorbidity experience, often distressing for Aboriginal community members and their families (5). Attempts to access comorbidity care had all too often resulted in limited, culturally inappropriate or no access (5). Also, in contemporary Australia, Aboriginal community members experience acts of racism and discrimination as health professionals and as consumers of health and support services(6). Added to this, the main author was an international student with no existing relationship with local Aboriginal community members or pre-existing cultural knowledge.

\section{Working with an Aboriginal mentor and an Aboriginal Working Party}

The CAN project research team included a respected Adelaide Plains Kaurna Aboriginal Elder Auntie Coral Wilson (ACW) who had worked in the area of research, drug and alcohol and mental health extensively. When HS began working with the project, ACW became her mentor, explaining what was important from an Aboriginal perspective, what was culturally appropriate, and introducing her to community members and key stakeholders. Six months later an Aboriginal Working Party (AWP) was formed, consisting of ten local Aboriginal people with $\mathrm{MH}-\mathrm{AOD}$ experience, who were interested in becoming co-researchers in the project. This group represented different genders and ages (AWP members 18 years and over, representing people of all ages) and diverse Aboriginal family and cultural groups. Major AWP meetings were held bi-monthly, with phone conversations, emails and face-to-face meetings in between. This flexible partnership enabled information sharing, problem solving and networking. HS had both formal and informal discussions with group members about what the research focus should be, how the research should be conducted, who else from the community should be involved and how they might engage with the project. The research approach was contextualised within the everyday needs and stressful events that affect families when caring for their MH-AOD dependent family members. This was communicated to the wider Aboriginal community with the assistance and guidance of mentor ACW and the AWP.

Alongside this process, HS engaged with the research activities expected of any PhD student, including conducting a literature review, considering which methodology and method were most appropriate, and 
preparing ethics applications.

\section{Ethics}

The formal ethics approval process required by the university, Aboriginal specific ethics committee, the government health department, and non-government $\mathrm{MH}$ and $\mathrm{AOD}$ organisations was a long and complex 18-month process. It involved multiple discussions with key stakeholders, gaining letters of support from multiple community members, groups and $\mathrm{MH}$ and $\mathrm{AOD}$ services, and meeting national and state guidelines for conducting Aboriginal Health Research, including the National Health and Medical Research Council (NHMRC) of Australia ethical principles and values that guide research involving Australian Aboriginal people (7), which promotes actively involving participants in all phases of the research and legitimising their 'lived experiences'. The Aboriginal Health Research Ethics Committee of South Australia also has specific requirements and advised HS to collaborate and consult with the mentor (ACW) as co-researcher and with the AWP as an Aboriginal Reference group in each phase of the research process. When ACW was unavailable, another AWP member or local Aboriginal community member accompanied HS to meetings. This was openly discussed and agreed by all involved.

\section{Methods}

\section{Participatory Action Research}

While the wider CAN project had determined that a PAR approach was required for each phase, (8), the approach and details for the Aboriginal arm of the project were still to be determined. As with the wider project, PAR was selected as the preferred collaborative approach because, from the participants' perspective, it enabled deeper understanding of the research problem in order to find appropriate and responsive action-oriented solutions (9).

As HS began to explore possible approaches to the research, she became aware of the need to incorporate the diverse voices of local Aboriginal community members. Through conversation and reading, she had discovered that Aboriginal people had a more holistic view of life and connectedness within their communities, with nature and their country or land (10). She realised that she would need to go beyond Western interpretations of PAR in order to respond to the advice of her mentor and the AWP, and Indigenous Research ethics guidelines.

\section{Yarning}

HS sought to create a research approach underpinned by Aboriginal values and culture that was reciprocal and involved transparent knowledge sharing. She felt it was essential to truly consult with the local Aboriginal people about their needs and priorities, then present their opinions in their own voices, without the filter of her or other researchers' assumptions. The research process began with consultations in the form of "Yarning", which involves a free-flowing, uninhibited conversation and deep listening in an environment in which (the intention was) all participants felt safe and respected (11). Yarning promoted active participation and interaction, strengthened partnerships, communication, responsibility and 
accountability; it created a space where the whole team and community members were able to face ongoing challenges together. Using Yarning principles, respectful and collaborative approaches to data collection, interpretation and categorisation of findings were made possible, enabling the best opportunity for potential application of realistically implementable, on-the-ground solutions (12)

\section{Learning about and understanding the importance of 'Dadirri' (deep listening): Establishing trust}

The next step involved gaining an understanding of the importance and process of deep listening. 'Dadirri' (13) is an Aboriginal word meaning inner, deep, quiet listening and a profound awareness of the "deep spring of sentience that comes from within" (14). In simpler terms, Dadirri means patient listening with understanding to enhance real communication, which is the heart of conversation. Dadirri encourages transparency about who we are and what we hope to achieve, and in research, what benefit research brings and for whom (15). Dadirri recognises that individuals who are more 'comfortable' with each other build mutual trust, and exchange information more effectively than individuals who have less contact or are less at ease. West et al. (2012) observed that Dadirri brings peace, understanding and increased awareness. Thus, Dadirri enables an unbiased, trusting and respectful relationship to be built and maintained.

Dadirri is a concept that the Ngangikurungkurr (river people) from Daly River in the Northern Territory of Australia have chosen to share. Dr Ungunmerr-Baumann, an Elder of Daly River who was also the Principal of Daly River School, explains that Aboriginal people have endured learning the Western way and listening to what Western people say for many years, and while much of this was acceptable, some was obligatory; Aboriginal people were forced to listen. She said, "We still wait for fellow Australians to take time to know Aboriginal people and to be still and to listen to us" (16). She insisted that listening and learning must go both ways; Aboriginal and Western knowledge must come together without one ruling the other. Reflecting deeply on her words, HS acknowledged that it was important to recognise and respect Aboriginal knowledge and incorporate it into the development and enacting of the methodology.

HS realised that the fundamental elements of Dadirri, of mutually respectful interpersonal and social interactions, were important due to the past and ongoing impact of colonisation; from initial invasion, to Stolen Generations when Aboriginal children were forcibly removed from their families(14), to ongoing marginalisation and racism. HS discovered that not a single Aboriginal family she spoke to was untouched by the impact of these events, with resulting mental health and alcohol and drug implications; all shared these stories. Knowing this history was essential to understanding the unique spiritual and cultural attributes, and the challenges many Aboriginal people experienced. These challenges, however, remain misunderstood and unrecognised by the majority of non-Aboriginal people (17). In order to do no harm, and to avoid colonising assumptions and trends within this research project, it was important to first listen deeply and attentively.

Dadirri encourages recognition of the uniqueness and diversity each individual brings to a community, and the importance of this diversity within a 'whole' community. It considers ways of relating and acting 'within' community. There is an emphasis on the process of contemplation with an in-depth 
understanding and awareness of one's 'thoughts, words and deeds', from within and without (18); of not rushing into things but waiting for the right time to do them with care (19). Deep listening is non-intrusive, reflective and non-judgemental. It considers what is and what is not being said. It is a responsible process of purposeful planning to act, based on learning, listening and being informed by wisdom and knowledge (20). It is non-judgemental watching and listening from the heart and ears before acting in good faith (18). Profound deep listening creates knowledge; and when people's experiences are heard and acknowledged, it also brings healing. In this way, researchers who work with Aboriginal people using Dadirri are encouraged to venture beyond their basic academic responsibility of being 'just an investigator' and instead to work with Aboriginal people as co-researchers with the potential for enhanced wellbeing and healing.

\section{' Ganma': knowledge sharing}

Participatory Action Research (PAR) is a useful framework to bring research processes together; PAR can assist researchers to focus on real issues that affect real people by clarifying how things happen, and how the people concerned perceive their situation, infer the need for change and respond by taking action (21). It creates a process where people who are confronted with similar issues identify and reflect on their experiences to find an effective solution (22). PAR has the potential to improve outcomes for the wider community through community members' involvement in the research design and action (23). Therefore, PAR is a systemic approach to investigation that enables people to consider and find effective solutions to problems that they (and their communities) confront in their everyday lives (24). But how was HS to bring all of the voices and viewpoints together? How was she, a non-Indigenous international PhD student, to write a truly comprehensive research report and a thesis that honoured the many voices and perspectives she was hearing? For inspiration, she turned to another Indigenous cross-cultural concept called 'Ganma'.

The Yolgnu people from Arnhem Land in the Northern Territory of Australia describe Ganma as respectful two-way sharing of cultural knowledge and interaction between Aboriginal and non-Aboriginal people (Yunupingu \& Watson, 1986, in Muller, 2012). Ganma refers to both a naturally occurring phenomenon involving two river systems on Yolgnu lands, and a way to improve relationships between Aboriginal people and non-Aboriginal people (25). Aboriginal knowledge' represents water from the river (fresh water), and 'Western knowledge' (non-Aboriginal knowledge) represents water from the sea (salt water). When these waters run together at an interface they mix with each other to form a foam that is the creation of new knowledge generated from the interaction and collaboration of Aboriginal and Western knowledge (26). By sharing their cultural understanding of Ganma, Aboriginal people have also shared how Aboriginal and Western peoples and knowledges can collaborate while maintaining their separate identities.

Ganma describes the context of collaboration, interaction and knowledge-sharing phenomena whereby each person is mindful of the other's individual and combined experiences, and their contribution to the collaboration (Yunupingu\& Watson, 1986, in Muller, 2012). It provides the pathway for connecting people 
and bringing them to actively work together to create new knowledge that is not claimed as 'mine' or 'yours', but as 'ours' (27). The process of knowledge-sharing and interaction has memory; forgetting people's history can lead to losing one's identity (28). The foam retains individual particles of both fresh water and salt water, which continue to carry their own identities and memory. The Yolgnu people explain that if the foam (knowledge) is cupped roughly in the hands, it evaporates; it must be held gently to reveal its true nature. It is also necessary to be quiet and patient, and to listen deeply to hear the foam's soft sound (28). In this way, Ganma is closely linked to Dadirri.

HS reflected that similarly, ACW and members of the local AWP had explained to her that for people to understand and work with Aboriginal ways of living and culture, they need to 'work with sheer good heart (understanding), mind (attitude) and hands (skill) to render sharing hands to walk together' (Field Journal, 2012), respecting the integrity of both Aboriginal and non-Aboriginal cultures (27).

When HS took these concepts back to ACW and AWP members for discussion, all identified that linking PAR with Ganma was justified and respectful. Although this knowledge sharing concept originated on the other side of Australia, the key elements of Ganma resonated with their own cultural understandings and philosophy. There was recognition that combining Ganma and PAR would enable a cross-cultural community development approach that recognised the importance of local Aboriginal people identifying and defining the problem requiring research; it would also prevent external researchers from working in isolation from the community (29).

\section{Community Development Concepts}

Further discussion identified that this new PAR-Ganma approach could enable deeper exploration of the complex situations that were occurring for Aboriginal peoples in relation to $\mathrm{MH}$ and AOD morbidities. This provided potential for the health and wellbeing of the local community to improve through involvement in research; if their stories were heard, and their knowledge was respectfully incorporated, the results could inform culturally safe and responsive improvements in service provision. The suburbs where this research was situated are recognised as having significant socioeconomic disadvantage. Combining PAR with Ganma could help to describe the landscape of social and economic arrangements, as well as cultural implications, to identify why 'health for all' is not always possible for all community groups within capitalist societies (17). The Ganma-PAR process also had the potential to bring together the knowledge and experiences of consumers and MH-AOD comorbidity service providers, enabling a more balanced understanding of the realities of health issues and health service responses. Potentially this process could also assist service providers to critically analyse their service provision and take appropriate action to improve their services in response to community information and feedback.

\section{Self-determination, critical theory and partnerships}

As part of her PhD learning process, HS continued to review literature about what constituted good Aboriginal health research and critically reflected on the extent to which she was able to incorporate these 
concepts into the project. She increasingly understood that Aboriginal people's battle against oppression influenced their evaluation of whether a research activity was justifiable and respectful, or colonising. She read key influential authors who had identified ways to incorporate self-determination into Aboriginal research processes within South Australia. Indigenous scholar Rigney (1999) proposed three main principles of Aboriginal research as being emancipation, political integrity and privileging Aboriginal people's voices. He argued that critical theory concurs with an Aboriginal view of the 'just world', promoting recognition of self-determination and attempting to affirm the individual and the community through political freedom and sociocultural liberation.

Non-Indigenous researchers de Crespigny, Emden (30) described a Partnership model for ethical Indigenous research that provided a culturally-safe, holistic, ethically-sound Aboriginal research approach with four key features for creating collaborative engagement with Aboriginal people; 'Respect', 'Collaboration', 'Active Participation' and 'Meeting Needs' (30). This Partnership Model recognised the need for flexibility, reciprocity (benefit in return) and mutual obligation, recognising that at times community members needed to attend to community responsibilities before research responsibilities. These concepts linked closely to the ethical guidelines for Aboriginal research $(7,30)$.

\section{Including Key Stakeholders}

Collectively HS, ACW, the AWP members and the wider CAN research team also recognised the importance of involving other key stakeholders during the development of the research project to ensure engagement, support and participation (21). Making meaningful changes in MH-AOD comorbidity service delivery required inclusion of a diverse range of knowledges - those of government and non-government service providers, clinicians, managers, coordinators and support services - and their roles. Working relationships needed to be built and maintained. HS began meeting with different people and groups providing co-morbidity services and support services, building relationships and inviting suggestions for the project. This process of inclusion began with the ethics approval process and continued through all phases of the research.

\section{Critical Theory}

HS identified critical theory as the most appropriate approach for this action-oriented project because critical theory encourages the questioning of power, socio political and economic ideologies. In particular, Habermas, a second-generation critical theorist, introduced the idea of emancipation through mutual understanding, appropriate communication and critical reflection (31). Crotty suggested that critical research could uncover hidden domination and oppression, and enable exposure and analysis of power systems, thus contributing to liberation through change (32). Freire (33) argued that marginalised people's wisdom and knowledge is the best resource for achieving realistic solutions to the issues they encounter in everyday life. This resonates with processes of self-determination that give voice to Aboriginal people, rather than having others talking on their behalf (34). Critical theory promotes 
liberation and identifies and challenges power structures (35). As such, HS recognised that it could encourage consumers and service providers to look deeply into the service provision system to analyse consumer utilisation, satisfaction and benefit. It had the potential to support Aboriginal people's selfempowered action for transformative change in their health status. Using critical theory as a basis could even possibly enable a greater conscious awareness of political structures within the health care system and existing barriers to care, thus enabling structural and service modifications to meet community needs.

\section{Post-colonial Theory}

HS and the research team also used post-colonial theory as described by Smith (2001) to shape the methodology. Post-colonial theory identifies the importance of recognising that colonisation is ongoing and continues to impact negatively on people's lives, health, well-being and social determinants of health, and acts to disempower them (rather than assuming that Australia is in a post-colonial period where the effects of colonisation are no longer felt). Smith identified that the ongoing impact of colonisation is an important reason why Indigenous peoples distrust Western research. Therefore, any research involving Indigenous peoples must be de-colonising in intent, highly accountable, focus on self-determination and involve deep critical reflection by non-Indigenous researchers. Post-colonial theory reinforces the importance of examining underlying structures of power, historic institutionalisation and different forms of oppression (14). A decision was made collaboratively by HS, ACW, AWP members, the CAN team and supervisors at the AWP meeting to predominantly use critical theory as the overarching theory for this comorbidity study, but to look very deeply at the grassroots level using Dadirri and Ganma to understand the primary causes of power imbalances linked to colonisation and how these impacted on $\mathrm{MH}$ and $\mathrm{AOD}$ comorbidity care access.

Collectively, the concepts Yarning, Dadirri, Ganma, community development, self-determination, partnership, critical theory and post-colonial theory were brought together to inform and develop an approach to PAR most appropriate for exploring and potentially improving $\mathrm{MH}$ and AOD comorbidity services with, and for, Aboriginal peoples. It was anticipated that this approach would enable Aboriginal community members' full engagement with the research process, integration of their knowledge and approaches, and inbuilt flexibility and sustainability that respected their needs in terms of fulfilling their cultural responsibilities. Importantly, it also had the potential to accelerate the shift towards local Aboriginal community members being recognised as accountable partners, advisors and advocates in research.

\section{Results: Constructing A Par Framework}

HS adapted Kemmis, McTaggart (9) reflective framework of communicative action with four phases, and incorporated Dadirri and Ganma throughout each phase, as shown in Fig. 1 and 
understanding how each element of Dadirri interacted with PAR enabled HS to co-develop a respectful approach with ACW and the AWP. Together they listened to the diverse voices of local Aboriginal people respectfully and democratically. $(19,20,36)$. Closely aligned with Freire's concept that the 'best way to learn is by doing and the best way to do is by learning' (37), the combination of Dadirri and PAR enabled information and knowledge to be shared and interpreted at the same time Truly collaborative approaches, with Indigenous governance and decision making (preferably adequately funded) are crucial for these to be acceptable and effective.

Thus, as illustrated in Fig. 2, both Aboriginal knowledge systems and Western methods of knowledge exchange were used in synergy.

HS also developed a visual representation of the methodology and methods that enabled her, ACW and the AWP to discuss, debate and explain the methodology. This is available in an earlier publication and HS's thesis $(2,8)$.

\section{Using The Methodology}

Once developed, the methodology was used to begin conducting the research project, and HS, ACW and the AWP continued to reflect on and refine the methodology in response to interactions and findings within the research project. This interaction closely aligns with Rigney's $(38,39)$ position that Aboriginal people's diverse experience should underpin construction of the methodology - their voices must be heard. The Aboriginal Health Research Ethics Committee's expectation is that research processes are responsive to need (40). Repeated cycles of look and listen, think discuss, collaborate, consult, plan and take action were used throughout the project. Concepts of Yarning, Ganma and Dadirri underpinned all interactions, and critical and post-colonial theory helped to shape interpretation and action.

This was particularly apparent in the way the final workshop was developed to confirm findings of the project with participants. HS was particularly concerned about how to balance ethical dimensions of honouring the mutual research relationship, co-producing findings of the project, developing recommendations with all participants (community members comorbidity and support service staff) while being mindful of Western dominance, and writing up the research as a thesis which would ultimately be in her own words, and would benefit herself. HS, ACW and the AWP discussed the need to create a 'fair play ground' where all information was acknowledged and respected. Using principles of Yarning, Dadirri and Ganma they discussed between themselves, and with other participants and key stakeholders, the best way forward. Key stakeholders included members of the wider CAN research project, the Aboriginal Health Council of South Australia and the local council. The workshop planning, facilitation and generation of agreed recommendations involved diverse groups and became an integral part of the whole PAR process, reinforcing and incorporating the methodology chosen.

The final workshop was held in the local area, enabling local Aboriginal participants to be involved in decision making more easily and meaningfully. Support service providers, their managers and other key 
stakeholders were invited to attend. There was an open invitation for anyone interested to be involved in planning the workshop. Two staff from the Aboriginal Health Council of South Australia facilitated the workshop to create a safe space for Aboriginal community members to address power dynamics, and skilfully enable complex conversations toward agreed recommendations. Respectful listening (Dadirri) and self-reflective knowledge sharing (Ganma) underpinned the approach. Small table discussions and note taking (Yarning) enabled all opinions and feedback to be heard.

\section{Discussion}

Aboriginal people have been researching and working together, reviewing and improving the health and wellbeing of their communities for thousands of years, and they shared this collaborative approach with HS. The written explanations of Yarning, Dadirri and Ganma helped HS to understand the concepts theoretically; and working alongside ACW and the AWP enabled her to learn and practice the skills of utilising these approaches. HS learned how to work respectfully in this collaborative intercultural space whilst also meeting deadlines and budgets. She learned the important skill of facilitating by 'gently holding' a group of people together, but not too tightly (as described in Ganma), valuing everyone's opinion and reading consensus. This research project was built collaboratively from the ground up, focused on an issue of great concern to the local Aboriginal community, and had the potential to inform service improvements and system changes. The research project was not primarily focused on the needs and priorities of the PhD student; rather, the research project was focused on the needs and priorities of Aboriginal community members and the challenges facing MH-AOD staff and services.

The partnership that developed between HS, Auntie Coral Wilson (ACW, the Aboriginal Elder/mentor/researcher) and the Aboriginal Working Party (AWP) was central to the success of this methodology and the methods used to investigate MH-AOD comorbidity care. Ongoing, transparent communication helped to build trust between team members, and the team and the wider Aboriginal community and service providers. This process was as important as the findings because it enabled a deeper discussion and identification of the different elements needed for improving and restructuring $\mathrm{MH}$ AOD services.

At a personal level, these deep relationships and deep listening posed a significant challenge for HS. Many Aboriginal people experiencing $\mathrm{MH}$ and AOD issues are also impacted by colonisation, stolen generations and racism. These are difficult conversations to hear and be present in. HS found that she needed to develop strategies that enabled her to listen deeply to emotionally distressing information, and then balance responding to Aboriginal participants' individual issues with the collective needs of diverse Aboriginal participants and stakeholders, and the role of research coordinator. ACW and the AWP assisted her in developing strategies because these are the kind of challenges they face daily in their own work.

One ethical concern that is often raised in relation to collaborative research involving Aboriginal community members is remuneration and recognition (41). In this research project, the university employed ACW as a co-researcher and mentor, and the majority of the AWP were employed in MH and 
AOD or support roles and attended as part of their working hours, with the support of their team leaders and managers. Interviews and focus groups with community members were held at a time and location most suitable for participants (to reduce inconvenience). Although participants were not financially remunerated (a decision supported by the wider CAN project and the Aboriginal Health Research Ethics Committee at the time), refreshments and transport assistance were provided, particularly at the longer final workshop, in which 60 community members and local service providers participated. The local council provided the workshop venue free of charge, transport assistance was arranged through a variety of means, and catering was provided from the project budget. Feedback from community members was that they attended because they saw HS's genuine concern for, and engagement with, their shared experiences of MH-AOD service provision, and they saw the potential for this PAR project to make a change. They also discussed how they had been involved in repeated studies that paid 'lip service' to their concerns, but no action to improve access or services had been taken.

Another concern often raised is whether each participant's voice is heard equally. The methodology and methods used in this project addressed this in several ways. While ACW was an Elder, mentor and coresearcher, she firmly believed in the importance of a range of voices being heard. The AWP used collective decision making processes that respected the Elder's leadership but also ensured that all voices were respected and a range of opinions were incorporated into each decision. The concepts of Dadirri and Gama were embedded into the way the research team members interacted among themselves, as well as how the research incorporated the viewpoints of wider community members and MH-AOD and support service staff in interviews, focus groups and the final workshop. Dadirri and Ganma underpinned all stages of the research, beginning with planning and data collection through to analysis and writing recommendations for action. This process reminded HS to avoid making assumptions and unilateral decisions about what might be most appropriate for the AWP, other participants and the wider Aboriginal community in terms of the research process and recommendations for improvements in comorbidity care.

\section{Research limitations}

The more recent development of decolonising methodologies and increasing use of Indigenous methodologies and methods such as Yarning, Dadirri and Ganma offers new approaches and understanding for Aboriginal health research, and provides a clearer positioning of Indigenous and nonIndigenous researchers. If further stages of this project were to be conducted, decolonising methodologies rather than post-colonial theories would be used to inform research planning, collaborative research processes and outcomes. Future research projects would endeavour to include an increased budget to cover payment for community member participation (sitting fees, transport and catering costs). With the increase in the number of Aboriginal and Torres Strait Islander researchers and higher degree students, there has been a much needed prioritisation of Indigenous people undertaking Indigenous research. However, the extent and breadth of health care challenges and current ethical agreements are such that within Australasia, non-Indigenous researchers will still be actively involved, at times as PhD candidates. Truly collaborative approaches to Indigenous governance and decision making 
that represent diverse Aboriginal viewpoints and ages process (preferably adequate and sustainable funded) are crucial for these to be acceptable and effective.

\section{Conclusion}

This paper describes the process of co-design undertaken by an international PhD student working in deep collaboration with Aboriginal mentors and an Aboriginal working party in a MH-AOD comorbidity needs study. Unlike traditional hegemonic research, this collaborative PAR was underpinned by Indigenous concepts of Yarning (talking together), Dadirri (deep listening) and Ganma (knowledge sharing). This approach enabled and reflected a mutual and trustworthy partnership and reciprocal relationship, resulting in a research methodology that was fit for purpose; it encouraged diverse participants to be heard and actively co-design recommendations for changes in care provision. It is hoped that this example of genuine research collaboration among the very people impacted by the scourge of MH-AOD comorbidity (largely resulting from the effects of colonisation and compounded by inadequate service provision), service providers and an international $\mathrm{PhD}$ student, will provoke serious questioning among the research community about how to learn to elicit the deepest knowledge, true partnerships and workable solutions to problems experienced by diverse communities world wide.

\section{Declarations}

Ethics approval and consent to participate: $\mathrm{H}-2012-088$ Human Research Ethocs Committee, REC2487/6/15 (HREC/12/WCHN/22; SSA/12/WCHN/24) Women's and Children's Hospital Human Resaerch Ethics Committee, SSA/12/TQEHLMH/113 Human Resaerch Governance Office (TQEH/LMH/MH) SA Health, Angli Care Research Ethics, Committee, SSA/13/SAH/16 SA Ambulance Servcie

Consent form: Attached

Availability of data and materials: Yes

Competing interest: No

Funding: Australian Research Council Linkage through the University of Adelaide

\section{Authors contribution:}

Conceptualization: Hepsibah Sharmil, Coral Wilson, Janet Kelly, Charlotte de Crespigny, Cherrie Galletly, Margaret Bowden, Imelda Cairney, Joanne Else

Data Curation: Hepsibah Sharmil, Coral Wilson

Formal Analysis: Hepsibah Sharmil, Coral Wilson 
Funding acquisition: Charlotte de Crespigny, Cherrie Galletly

Investigation: Hepsibah Sharmil, Coral Wilson, AWP

Methodology: Hepsibah Sharmil, Coral Wilson, AWP

Project administration: Hepsibah Sharmil, Coral Wilson, Charlotte de Crespigny, Imelda Cairney, Cherrie Galletly, Joanne Else, Dennis Liu

Resources: Cherrie Galletly, Charlotte de Crespigny, Imelda Cairney,

Supervision: Charlotte de Crespigny, Cherrie Galletly, Janet Kelly

Writing - original draft: Hepsibah Sharmil, Margaret Bowden

Writing- review and editing: Janet Kelly, Charlotte de Crespigny, Margaret Bowden, Cherrie Galletly , Lisa Hahn, Hepsibah Sharmil, Dennis Liu, Imelda Cairney

Acknowledgement: Aboriginal Working Party (AWP): Ms. Coral Wilson, Mr. Paul Elliot, Ms. Joanne Else, Mr. Trevor Warrior, Mr. Trevor Wanganeen, Mr. Robert Taylor, Mr. Frank Wanganeen, Mr. Jodus Madrid, Ms. Lisa Warner and Ms. Mandy Brown. Thanks to Mr. Robert Dann and Ms Rosie King, Aboriginal CAN workshop facilitators.

\section{References}

1. Smith L. Decolonizing methodologies: Research and Indigenous peoples. 2 ed. London: Zed books; 2012.

2. Francis Jebaraj $\mathrm{H}$. Stopping the Run-around: Addressing Aboriginal community people's mental health and alcohol and drug comorbidity service needs in the Salisbury and Playford local government areas of South Australia Australia University of Adealide 2015.

3. Habibis D, Taylor PS, Ragaini BS. White people have no face: Aboriginal perspectives on White culture and the costs of neoliberalism. Ethnic Racial Studies. 2020;43(7):1149-68.

4. Yashadhana A, Fields T, Blitner G, Stanley R, Zwi AB. Trust, culture and communication: determinants of eye health and care among Indigenous people with diabetes in Australia. BMJ Global Health. 2020;5(1).

5. Gray D, Stearne A, Bonson M, Wilkes E, Butt J, Wilson M. Review of the Aboriginal and Torres Strait Islander alcohol, tobacco and other drugs treatment service sector: harnessing good intentions: National Drig Research Institute (NDRI), Curtin University; 2014.

6. Lawson C, Woods D, McKenna T. Towards Indigenous Australian knowing. Art Therapy in Australia: Brill Sense; 2019. p. 77-105.

7. Ethical guidelines for research with Aboriginal. and Torres Strait Islander [Internet]. Australian Government 2018 [cited 29 May 2019]. 
8. Liu D, De Crespigny C, Procter N, Kelly J, Francis H, Posselt M, et al. Comorbidity Action in the North: a study of services for people with comorbid mental health and drug and alcohol disorders in the northern suburbs of Adelaide. Australasian Psychiatry. 2016;24(6):592-7.

9. Kemmis McTaggartR, Nixon R. The action research planner: Doing critical participatory action research: Springer Science \& Business Media; 2013.

10. Henderson G, Robson C, Cox L, Dukes C, Tsey K, Haswell M. Social and emotional wellbeing of Aboriginal and Torres Strait Islander people within the broader context of the social determinants of health. In: Anderson I, Baum F, Bentley M, editors Beyond Bandaids: Exploring the underlying social determinants of Aboriginal Health: Cooperative Research Centre for Aboriginal Health 2007. p. 13664.

11. Bessarab D, Ng'andu B. Yarning about yarning as a legitimate method in Indigenous research. International Journal of Critical Indigenous Studies. 2010;3(1):37-50.

12. Grierson E, Brearley L, Hamm T, Duxbury L, Barnacle R, Downton P, et al. Creative Arts Research: Narratives of Methodologies and Practices. Melbourne: Royal Melbourne Institute of Technology University, RMIT; 2009.

13. Ungunmerr-Baumann M. Dadirri: Inner Deep Listening and Quiet Awareness Emmaus Productions; 2002 [Available from: http://www.liturgyplanning.com/documents/main.php? g2_view=core.Downloadltem\&g2_itemld=4696.

14. West R, Stewart L, Foster K, Usher K. Through a critical lens: Indigenist Research and the Dadirri method. Qual Health Res. 2012;22(11):1582-90.

15. Adams K, Faulkhead S. This is not a guide to Indigenous Research Partnership: But it could help. Information Communication Society. 2012;15(7):1016-36.

16. About Dadirri [Internet]. Miriam Rose Foundation 1988 [cited 3 June 2019]. Available from: http://www.miriamrosefoundation.org.au/about-dadirri.

17. Gee G, Dudgeon P, Schultz C, Hart A, Kelly K. Aboriginal and Torres Strait Islander social and emotional wellbeing. Working together: Aboriginal and Torres Strait Islander mental health and wellbeing principles and practice. 2014;2:55-68.

18. Atlkinson J, Graham J, Pettit G, Lewis L. Broadening the focus of research into the health of Indigenous Australians. Med J Aust. 2002;177:286-7.

19. Creative Spirit. Deep listening (Dadirri) explained 2012 [updated 7 November 2012 I. Available from: http://www.creativespirits.info/aboriginalculture/education/deep-listening-dadirri\#toc2.

20. Stronach A. 'Dadirri': Reflections on a research methodology used to build trust between a nonindigenous researcher and indigenous participants. Cosmopolitan Civil Societies: An Interdisciplinary Journal. 2014;6(2):117.

21. Stringer. Action research. 4th ed. Los Angeles: Sage publications; 2013. 299 p.

22. Blodgett AT, Schinke RJ, Peltier D, Fisher LA, Watson J, Wabano MJ. May the circle be unbroken: The research recommendations of Aboriginal community members engaged in participatory action research with university academics. Journal of Sport Social Issues. 2011;35(3):264-83. 
23. Kemmis. McTaggart, Nixon. Critical Participatory Action Research'. Action Learning and Action Research: Genres and Approaches Emerald Publishing Limited. 2019:179-92.

24. Stringer ET. Action Research. 3 ed. Los Angeles: Sage Publications; 2007.

25. McLaughlin M. Crossing cultural borders: A journey towards understanding and celebration in Aboriginal Australian and non-Aboriginal Australian contexts: Curtin University Perth, WA; 2012.

26. Chambers D, Turnbull D, Watson H. Singing the Land, Singing the Land: Geelong; 1989. Available from: http://singing.indigenousknowledge.org/.

27. Hughes I, editor Ganma: Indigenous Knowledge for Reconciliation and Community Action. Participatory Action Research World Congress; 2000; School of Behavioural \& Community Health, The University of Sydney.

28. Pyrch T, Castillo MT. The sights and sounds of Indigenous knowledge. In: Reason P, Bradbury H, editors. Handbook of Action Research, Participative Inquiry and Practice. London: Sage; 2001. pp. 379-85.

29. Carr W, Kemmis S. Becoming Critical: Knowing through Action Research. reprint ed. Victoria: Deaken University 1986 2003. 260 p.

30. de Crespigny C, Emden C, Kowanko I, Murray H. A 'partnership model' for ethical Indigenous research. Collegian: Journal of the Royal College of Nursing Australia. 2004;11(4):7-13.

31. Crotty M. The Foundations of Social Research, Meaning and perspective in the research process. Sydney: Allen Unwin; 1998.

32. Harvey L. Critical social research: Contemporary Social Research. London: Unwin Hyman; 1990. 19 October 2013.

33. Freire P. Pedagogy of the opperessed. New York: Seabury Press; 1970.

34. de Villiers B. A fresh approach to Aboriginal self-government and co-government-grassroots empowerment. Brief. 2020;47(1):10.

35. Poster M. Critical theory and poststructuralism: In search of a context: Cornell University Press; 2019.

36. Stronach A. Dadirri. Using a philosophical approach to research to build trust between a nonindigenous researcher and Indigenous participants. Cosmopolitan Civil Societies: An Interdisciplinary Journal. 2014;6(2):117-34.

37. Freire P. Pedagogy of the city. New York: Continuum; 1993.

38. Rigney L-I. Internationalization of an Indigenous anticolonial cultural critique of research methodologies: A guide to Indigenist research methodology and its principles. Advancing International Perspectives. 1999;14(2):632-9.

39. Rigney L-I. Indigenist Research and Aboriginal Australia In: Kunnie J, Goduka NI, editors Indigenous Peoples' Wisdom and Power: Affirming Our Knowledge Through Narratives Aldershort: UK: Ashgate; 2006. p. 32-50.

40. SAHMRI. South Australian Aboriginal Health Research Accord. Companion Document 2014 [Available from: https://ahcsa.org.au/research-overview/ethical-review-ahrec/. 
41. Posselt M, Galletly C, De Crespigny C, Cairney I, Moss J, Liu D, et al. Ethics overload: impact of excessive ethical review on comorbidity research. Mental Health Substance Use. 2014;7(3):184-94.

\section{Tables}


Methods

Phase 1: Look and listen -knowledge sharing using Yarning, Dadirri and Ganma, listening carefully to a diverse range of participants. The participants consist of three groups who were all involved in comorbidity care in the region; Group A-Participants from the local Aboriginal community who would act as consumer advocates, Group B - clinicians and workers from local MH and AOD services (government and non-government), and Group C - Workers from local support services (including emergency departments, ambulance and Aboriginal Health Workers, service coordinators, managers).
Data collection

Meetings with

- Aboriginal community members and groups, formal and informal discussions, building relationships

- local MH-AOD clinicians and workers

- support service staff

a three step process by HF and ACW with all participants

1. visit and introduce the project

2. in-depth conversation style interview or focus group

3. checking back that the manuscript was correct (member checking) 


\section{Methods}

Phase 2: Think and reflect; stepping back and reflecting on the shared knowledge using critical theory from both a Western and Indigenous understanding, with consideration of colonisation impacts. Deep consideration regarding access to culturally-appropriate $\mathrm{MH}-\mathrm{AOD}$ services, and research questions such as: How are MH-AOD services structured? Does this benefit Aboriginal consumers? How easy or difficult is it for Aboriginal consumers to get access to these services?

Data analysis - a collaborative process between HF and ACW

- Systematically organised contextual thematic analysis

- Interactive coding and categorising as themes

Identify

- Existing gaps in care, from multiple perspectives

- Strategies and services that are meeting Aboriginal comorbidity needs.

- Suggestions for improvement 


\section{Methods}

Phase 3: Collaborate, consult and plan using Dadirri and Ganma; interpreting and analysing the data together, and including the diverse knowledge, ideas and concepts shared. Concepts of mutual partnership ensured that the needs, perceptions and opinions of each person were considered, and no one person ruled over another, and no one person's knowledge was considered more important than another's. This needs to be a carefully negotiated approach that respects the role of senior Elders and Aboriginal consumers, yet also gives space for a range of voices and opinions to be heard. Rather than a step-by-step process following a set systematic (Western) formula, this process is based on mutual partnerships and respectful inclusion, discussion, disagreement and consensus making. This phase uses living knowledge to inform change, inviting participants and key stakeholders to work together to create an advanced, deeper level understanding and a practicable outcome.

Collaborative process led by HF and ACW

Emerging themes discussed with:

- Aboriginal Working Party

- Aboriginal consumer, $\mathrm{MH}-$ AOD \& support service participants

- Wider CAN research team.

Confirm findings with participants in a CAN Aboriginal workshop involving

all participants and the wider Aboriginal community

Discuss findings with participants and community members in an open public forum for them to confirm, refute or agree upon, in order to come up with the most appropriate solutions to best meet the Aboriginal community's MHAOD needs. 


\section{Methods}

Phase 4: Take action; a reflective cycle of consultation and action, which is repeated until a solution is reached (Blodgett et al., 2011). This phase involves carrying out the agreed plan of action in a collaborative, systematic, logical and appropriate way, and critically reflecting on each step. The process of "trustworthy action" arises through participation-mutual consultation, collaboration and collective reflection towards the collaborative-agreed goal (Kemmis \& McTaggart, 2007).

Community report of findings.

Agreed recommendations for Aboriginal $\mathrm{MH}-\mathrm{AOD}$ improvements and implementation in the local region

\section{Figures}

Start: Getting to know each other

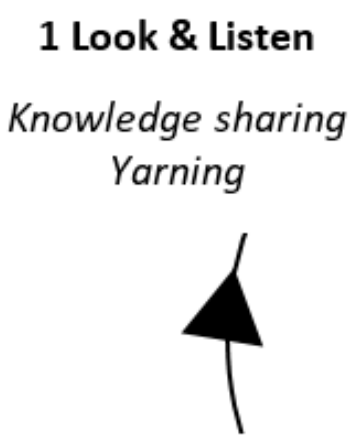

Take Action

Working together

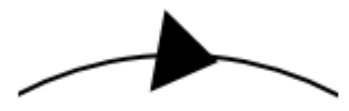

Dadirri

\&

Ganma

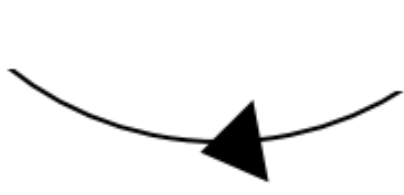

Repeated cycles in each phase

\section{Think \& Reflect}

Critical theory

Self determination

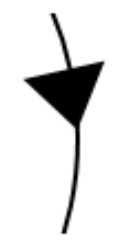

Collaborate, Consult \& Plan

Interpreting and Analysing

\section{Figure 1}

PAR INQUIRY CYCLE INCORPORATING DADIRRI AND GANMA 


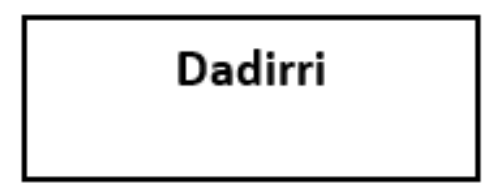

\section{Participatory Action Research}
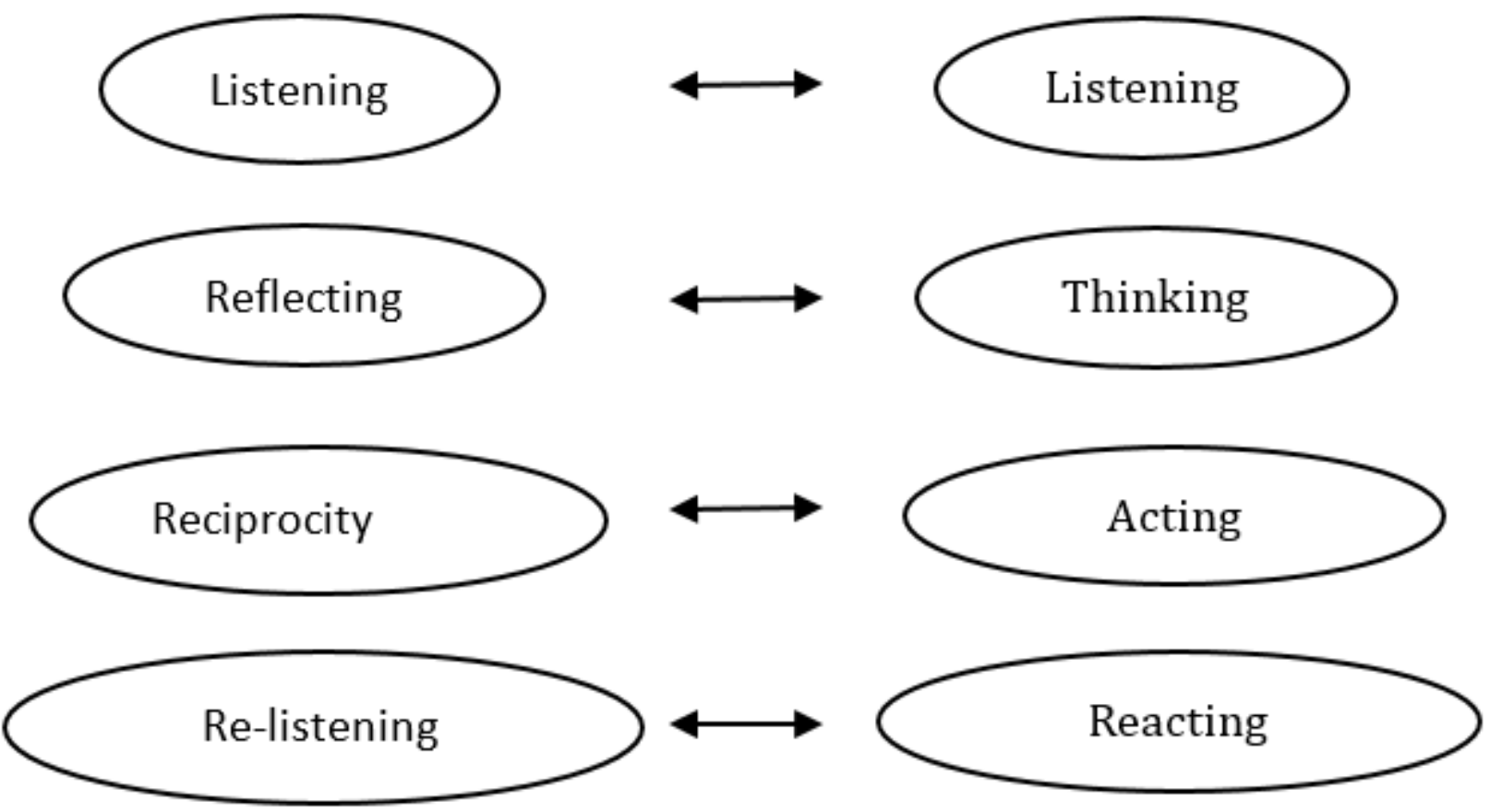

Figure 2

COMPONENTS OF DADIRRI AND THE PAR CYCLE [1] Francis Jebaraj, H., Stopping the Run-around: Addressing Aboriginal community people's mental health and alcohol and drug comorbidity service needs in the Salisbury and Playford local government areas of South Australia in School of Nursing 2015, University of Adealide Australia p. 376. 